\title{
FORMAÇÃO, TECNOLOGIA E INCLUSÃO: O PROFESSOR QUE ENSINA MATEMÁTICA NO "NOVO NORMAL"
}

\begin{abstract}
AMÉRICO JUNIOR NUNES DA SILVA
Universidade do Estado da Bahia (UNEB). Doutor em Educação pela Universidade Federal de São Carlos (UFSCar). Professor Permanente do Programa de Pós-Graduação em Educação, Cultura e Territórios Semiáridos (PPGESA/UNEB). Integra o Grupo de Estudos e Pesquisas em Educação Matemática (CNPq/UFSCar). ORCID: 0000-0002-7283-0367. E-mail: ajnunes@uneb.br
\end{abstract}

\section{ÉRICA SANTANA SILVEIRA NERY}

Universidade de Brasília (UnB). Mestra em Educação Matemática pela Universidade Estadual de Santa Cruz (UESC). Doutoranda em Educação pelo Programa de Pós-Graduação em Educação da Universidade de Brasília (PPGE/UnB). Integra o Grupo de Investigação em Ensino de Matemática (CNPq/UnB). ORCID: 000-0002-0571-1560. E-mail: ericaassilveira@gmail.com

\section{CLEIA ALVES NOGUEIRA}

Universidade de Brasília (UnB). Doutoranda em Educação pelo Programa de Pós-Graduação em Educação pela Universidade de Brasília (PPGE/UnB). Professora da Secretaria de Estado de Educação do Distrito Federal (SEEDF). Integra o Grupo de Investigação em Ensino de Matemática (CNPq/UnB). ORCID: 0000-0003-0983-2631. E-mail: cleianog@gmail.com 


\section{FORMAÇÃO, TECNOLOGIA E INCLUSÃO: O PROFESSOR QUE ENSINA MATEMÁTICA NO "NOVO NORMAL"}

Este artigo tem por objetivo refletir sobre os impactos e desafios impostos no momento atual de pandemia para a formação dos professores que ensinam Matemática no que se refere à efetivação de uma prática inclusiva com o uso das tecnologias digitais. Para isso, realizamos uma discussão teórica sobre as temáticas que emergem da problematização deste objetivo, a saber: formação de professores que ensinam Matemática, tecnologias digitais e educação inclusiva. Ao discorrermos teoricamente sobre cada uma dessas três temáticas, levantamos alguns desafios, que emergem do contexto pandêmico e apresentamos as interseções dessas três áreas de pesquisa, que nos possibilita compreender a educação, enquanto uma área de atuação, composta por um conjunto de subáreas que possuem relações e desafios semelhantes e que, por conseguinte, podem ser pensadas articuladamente. Com tais fundamentos, constatamos que perante o "novo normal", faz-se necessário repensar o ensino de Matemática desenvolvido nas instituições de ensino, com o intuito de incorporar novas tecnologias digitais e de considerarmos um ensino para todos, subsidiado pela concepção de acessibilidade enquanto um aspecto transversal que pode contribuir não apenas para o estudante ou professor que tem alguma Necessidade Educacional Específica, mas com todos os agentes envolvidos nos processos de ensino e aprendizagem. Ademais, para que todos esses aspectos possam se efetivar faz-se necessário, antes de tudo, uma formação docente pautada em uma práxis reflexiva, que possibilite aos professores analisarem continuamente a sua prática docente a luz de fundamentos teóricos. Além disso, torna-se necessária, a disponibilização de materiais adequados e acessíveis tanto para os professores quanto para os estudantes, para que os processos de ensino e aprendizagem sejam efetivos e contribuam para a formação humana e cidadã de todos os brasileiros.

Palavras-chave: Formação inicial. Formação continuada. Tecnologias digitais. Necessidades Educacionais Específicas. Acessibilidade.

\section{FORMACIÓN, TECNOLOGÍA E INCLUSIÓN: EL PROFESOR QUE ENSEÑA MATEMÁTICAS EN LA ERA DEL "NUEVO NORMAL"}

Este artículo posee como objetivo reflexionar sobre los impactos y desafíos impuestos en el momento pandémico actual, para la capacitación de profesores que enseñan matemáticas con respecto a la implementación de una práctica inclusiva con el uso de tecnologías digitales. Para esto, llevamos a cabo una discusión teórica sobre los temas que surgen a partir de la problematización de este objetivo, o sea: la formación de docentes que enseñan matemáticas, tecnologías digitales y educación inclusiva. Cuando discutimos teóricamente cada uno de estos tres temas, proponemos algunos desafíos, que surgen del contexto pandémico y presentan las intersecciones de estas tres áreas de investigación, eso nos permite entender a la educación como un campo de áreas de actividad que tiene relaciones y desafíos similares y que, por lo tanto, puede pensarse de manera articulada. Con tales fundamentos, encontramos que en vista de la "nueva normalidad", es necesario repensar a la enseñanza de las Matemáticas desarrollada en las instituciones educativas, para incorporar nuevas tecnologías digitales y considerar una enseñanza para todos, subsidiado por el concepto de accesibilidad como un aspecto transversal que puede contribuir 
no apenas al estudiante o profesor que posee una necesidad educativa específica, sino a todos los agentes involucrados en los procesos de enseñanza y aprendizaje. Además, para que todos estos aspectos sean efectivos, es necesario, sobre todo, una formación docente basada en una praxis reflexiva, que permita a los profesores analizar continuamente su práctica docente a la luz de los fundamentos teóricos. Además, es necesario proporcionar materiales adecuados y accesibles tanto para profesores como para estudiantes, para que los procesos de enseñanza y aprendizaje sean efectivos y contribuyan a la formación humana y ciudadana de todos los brasileños.

Palabras clave: Formación inicial. Educación continua. Tecnologías digitales. Necesidades educativas específicas. Accesibilidad.

\section{TRAINING, TECHNOLOGY AND INCLUSION: THE MATHS TEACHER IN THE "NEW NORMAL"}

This article has assessed teacher training in mathematics given the current pandemic situation and considering the implementation of an inclusive practice using digital technologies. We held a theoretical discussion on themes that emerge from this objective, considering the following areas: Mathematics teacher training, digital technologies and inclusive education, which can raise several issues and challenges in the pandemic context. The intersection of these specific areas of research allow us to understand education as a field composed by subareas with similar relationships and challenges, which should be considered in articulation. With this fundamental understanding in mind, it is necessary to rethink the teaching of Mathematics in view of what is being considered the "new normal". That it, consider the teaching of Mathematics developed in educational institutions considering the need to incorporate new digital technologies and a mathematical education for all. In this sense, we consider the concept of accessibility as a transversal aspect that can contribute to the development of, not only, the student or teacher with Specific Educational Needs, but of all the agents involved in the teaching and learning processes.Above all, to make these processes effective, it is necessary do stablish a process of teacher training that is based on a reflective praxis, that allows teachers to analyze their teaching practice continuously and in light of theoretical foundations. In addition, it is necessary to provide adequate and accessible materials for both teachers and students, to guarantee the effectiveness of the teaching and learning processes, and thus contribute to a human and citizen development of all Brazilians.

Keywords: Initial training. Continuing education. Digital technologies. Specific Educational Needs. Accessibility.

\section{plurais}




\section{FORMAÇÃO, TECNOLOGIA E INCLUSÃO: O PROFESSOR QUE ENSINA MATEMÁTICA NO "NOVO NORMAL"}

\section{Introdução}

O atual contexto de pandemia é propício para refletirmos sobre os inúmeros aspectos relativos à fragilidade humana e ao seu processo de ser e estar no mundo, que perpassam por questões culturais, educacionais, históricas, ideológicas e políticas. A pandemia, causada por uma doença contagiosa que se disseminou por todos os países, fez emergir outros problemas sociais existentes em cada parte do mundo, promovendo assim, a necessidade de constantes lutas pelo cumprimento dos direitos de todos, bem como, pela reinvenção de um "novo normal".

Esse movimento se traduz no que Santos (2020, p. 10) chamou de “[...] claridade pandêmica", isto é, quando um aspecto da crise, desencadeado pelas questões de saúde pública, faz emergir outras questões, como as relacionadas às desigualdades sociais, a exclusão, a discriminação, o desemprego, a falta de formação e informação; mas também, pode ser um momento catalisador de mudanças sociais que contribui para a construção de uma sociedade mais justa, igualitária e com um sentimento de pertencimento e de comunidade.

Nesse ínterim, ressaltamos que tudo depende da maneira como o contexto pandêmico é entendido pela sociedade, pois podemos, a partir das reflexões sobre este momento, avaliar as ações que estão sendo realizadas e como poderão influenciar na construção do futuro da civilização, para o estabelecimento de um "novo normal". Assim, trazendo tais aspectos para o campo educacional e considerando que "[...] a educação está entre as atividades mais elementares e necessárias da sociedade humana, que jamais permanece tal qual é, porém se renova continuamente através do nascimento, da vinda de novos seres humanos" (ARENDT, 2011, p. 234), pensamos no futuro frente às experiências desencadeadas pelo atual contexto.

As atividades educacionais brasileiras ainda estão em diferentes estágios, sejam paralisadas, realizadas de maneira remota ou de outras formas. O contexto escolar, diante dessa realidade, precisou se reinventar e passou a utilizar diferentes ferramentas tecnológicas que possibilitaram,

\section{plurais}


em alguns casos, a continuidade das atividades, assim que foi solicitado o distanciamento social. Os olhares, portanto, voltam-se às escolas e, principalmente, aos professores.

Nesse contexto, o ensino e a aprendizagem da Matemática têm se caracterizado, mesmo antes da pandemia, como um grande desafio, sobretudo pelos baixos resultados alcançados por um grande número de estudantes da Educação Básica do país e, como destaca Gatti (2010) e Gatti et al. (2019), pela estrutura de muitos cursos de formação. A pandemia, como apresentou Santos (2020, p. 6), "[...] vem apenas agravar uma situação de crise a que a população mundial tem vindo a ser sujeita". Esse momento tem levado os pesquisadores e gestores de políticas públicas a repensarem a escola e a formação dos professores no que tange a promoção de novas aprendizagens.

Destarte, não há como tratar todas as realidades da educação brasileira, principalmente no que se refere ao ensino e a aprendizagem da Matemática, com um único olhar, uma vez que “(...) a pandemia confere à realidade uma liberdade caótica e qualquer tentativa de aprisionar analiticamente está condenada ao fracasso, dado que a realidade vai sempre adiante do que pensamos ou sentimos sobre ela" (SANTOS, 2020, p. 13). Assim, os processos de ensino e aprendizagem de Matemática não podem ser tratados como uma fotografia, estática e sem movimento, pois é construída e consolidada por toda a comunidade educacional e social que se encontra em um momento atípico.

Com isso, além da emergência de saúde imposta pela pandemia, em âmbito social, vivenciamos também uma contingência na educação, a qual suscita alguns questionamentos, orientadores da escrita deste artigo, a exemplo: como desenvolver um ensino de Matemática que possa contemplar todos, em todas as suas singularidades? Como ensinar Matemática em um regime de atividades remotas? Como a Educação Matemática pode contribuir para o (re)pensar deste momento de pandemia? Como a pandemia pode contribuir para pensarmos a Educação Matemática no contexto do "novo normal"? Esses questionamentos nos inquietam e reafirmam a necessidade de repensarmos as práticas pedagógicas e contribuirmos para que a Educação Matemática, parafraseando Freire (2014), seja uma forma de intervenção no mundo, de maneira progressista, capaz de estimular e materializar os avanços necessários a atual e as futuras gerações.

Diante disso, faz-se necessário, perante o "novo normal", repensarmos sobre o ensino de Matemática desenvolvido até então em nossas instituições de ensino, assim como, sobre as demais questões relacionadas à educação, dentre as quais destacamos: a formação dos docentes, o uso de

\section{plurais}


tecnologias digitais e a educação inclusiva. Considerando tais aspectos e as nossas interrogações de pesquisa no doutoramento, é que temos por objetivo, neste artigo, refletir sobre os impactos e desafios impostos no momento atual de pandemia para a formação dos professores que ensinam Matemática no que se refere à efetivação de uma prática inclusiva com o uso das tecnologias digitais.

Esse direcionar ao contexto particular da Educação Matemática se deve a nossa imersão enquanto professores pesquisadores, com experiência na área de formação de professores, tecnologias digitais e inclusão, e pelo desejo de contribuir com o (re)pensar desse contexto e da promoção de reflexões que levem os gestores de políticas públicas a entenderem o lugar que as tecnologias digitais e a necessidade urgente de efetivação da inclusão ocupam no percurso da formação de professores que ensinam Matemática.

Este artigo, portanto, de natureza teórica e exploratória, divide-se em seções que foram estruturadas de forma a permitir ao leitor uma melhor compreensão das questões aqui abordadas; são elas: i) Introdução, onde contextualizamos a temática e apresentamos as questões e objetivos que nortearam a escrita deste texto; ii) Seções de desenvolvimento onde discorremos teoricamente sobre a formação de professores que ensinam Matemática, as tecnologias digitais e a inclusão na educação; iii) Seção em que articulamos as três áreas de discussão iv) E por último, algumas considerações.

\section{A formação do professor que ensina Matemática e os desafios reafirmados pelo contexto pandêmico}

Formar professores que ensinam Matemática no país, como sinalizaram as pesquisas realizadas por Fiorentini et al. (2002), Gatti (2010), Fiorentini, Passo e Lima (2016) e Gatti et al. (2019), tem se configurado, mesmo antes do contexto pandêmico, como um grande desafio. Esses desafios consistem no fato de que, por exemplo, muitas licenciaturas, são excessivamente teóricas e descontextualizadas da realidade da práxis escolar, como destaca Gatti (2010) e Santos (2002), ou, as redes de ensino não assumem a formação continuada enquanto responsabilidade. Isso, portanto, faz emergir a problemática que nos guiará na escrita desta seção: os professores que ensinam Matemática estavam preparados para as demandas (im)postas pela pandemia? Sabemos que nenhum curso preparou para a pandemia, uma vez que é uma situação atípica, mas entendemos que deveria preparar para as inúmeras demandas da atuação docente, principalmente, quanto à inclusão e ao uso das tecnologias digitais.

\section{plurais}


Por entender que a formação de professores que ensinam Matemática é o elemento desencadeador de nossa discussão, pensamos ser pertinente definir o que entendemos por formação inicial e continuada. Vale salientar que esses dois conceitos, embora distintos, devem ser compreendidos de forma articulada, sobretudo, pela ideia de formação enquanto um “continuum”. Enfatizamos também que o campo de formação de professores que ensinam Matemática, “(...) busca constituir uma identidade própria na Educação Matemática, com um olhar minucioso sobre a especificidade da formação para atuação na área” (CECCO; BERNARDI; DELIZOICOV, 2017, p. 1105).

Destarte, por "formação inicial" compreendemos o primeiro momento que prepara o sujeito para ingressar na profissão. Essa formação precisa ser entendida e vivenciada como espaço que ensine o futuro professor a aprender de modo contínuo e reflexivo; é nesse momento que o estudante, futuro professor, começa a se ver como professor, construindo sua identidade docente, como destacaram Brasil (2015), Pimenta (1999) e Silva e Passos (2020). Já a “formação continuada”, por sua vez, acontece para os docentes que possuem formação inicial e visa o aperfeiçoamento pessoal e profissional, tendo como foco os saberes, as técnicas e as atitudes necessárias ao exercício da profissão docente (FORMOSINHO, 1991).

É nesse movimento, pendular e dialógico, existente entre formação inicial e continuada, que entendemos circunscrito o conceito de continuum; que levando em consideração o que dissemos anteriormente e respaldando-se em Silva (2018), compreende a formação como um processo iniciado durante a graduação e que se estende ao longo de sua vida acadêmica e profissional. Dessa forma, ainda segundo o autor (2018), acreditamos que as experiências formativas oportunizadas durante a formação inicial devem ser vistas como ponto de partida e que deverão ser aprofundadas ao longo da formação continuada e das vivências propiciadas pelas experiências profissionais. Nessa direção, a escola ocupa um lugar de destaque, enquanto espaço de formação continuada para os docentes.

Entendendo que os desafios impostos pela contemporaneidade mudam continuamente, é importante entender que a formação de professores que ensinam Matemática é resultado de um processo dinâmico e que “(...) formar é mais ontológico que instruir ou educar: na formação, é o próprio ser que está em causa na sua forma” (FABRE, 1995, p. 23, tradução nossa). Por isso, esses professores também precisam reconhecer e assumir o seu papel nesse percurso formativo, entendendo que existem particularidades para quem ensina essa ciência. Não queremos responsabilizar unicamente os docentes por essa formação contínua, nosso intuito é, ao trazermos essa 
discussão, a circunscrevermos como parte de uma problemática sistêmica que tem outros agentes e espaços envolvidos.

Nessa direção, conforme evidenciou Nóvoa $\left(2020^{1}\right)$, “[...] se existe um momento em que a formação continuada dos educadores se faz essencial, este momento é agora. Precisamos discutir e compartilhar uns com os outros e reconstruir nossas aprendizagens". Importante assegurar, partindo do que apresentou o autor, espaços de aprendizagens para professores, principalmente em tempos de crise, em que se escancaram as desigualdades de acesso e de aprendizagens dos conceitos matemáticos. Por isso, é necessário (re)pensar esses espaços de formação e reconhecer o potencial das escolas e dos diferentes ambientes virtuais de aprendizagem.

Nesse ínterim, o contexto pandêmico, como destaca Cara $\left(2020^{2}\right)$ foi a "tempestade perfeita", para alimentar uma crise que já existia: os inúmeros problemas de aprendizagem da Matemática enfrentados pelos estudantes, a desvalorização docente, as péssimas condições das escolas brasileiras e da formação de professores, os inúmeros ataques à Educação, são alguns dos pontos que, para nós, caracterizam essa crise. A pandemia, ainda concordando com Cara (2020), só escancara o quanto a Educação no Brasil é reprodutora de desigualdades. Assim, será preciso repensar a formação, inicial e continuada, e a sala de aula de Matemática para um processo, como pontuou Nóvoa (2020), de reinvenção enquanto educadores em um pós-crise.

Reafirmando tal necessidade, o Centro de Inovação para a Educação Brasileira (Cieb) realizou uma pesquisa que tratou do ensino remoto no contexto pandêmico, divulgada em abril de 2020 , e apontou alguns dados alarmantes, como por exemplo, o fato de $60 \%$ dos municípios brasileiros que suspenderam as suas atividades presenciais, não possuírem estratégias digitais para atender os estudantes durante o isolamento social e que mais de $70 \%$ das redes municipais nunca tinham utilizado ferramentas ou metodologias on-line. Além disso, como barreiras que impedem a incorporação das tecnologias educacionais na Educação Básica, destacou-se a ausência dessa discussão na formação inicial e “(...) a maioria das secretarias de ensino, quando faz formação continuada

1 Informação apresentada oralmente por Antônio Nóvoa durante aula magna promovida pelo Instituto Anísio Teixeira (IAT), da Secretaria de Educação da Bahia, durante a abertura da Formação Continuada Territorial à Distância, em abril de 2020. Link: https://www.youtube.com/watch?v=7kSPWa5Nieo.

2 Informação apresentada oralmente por Daniel Cara durante palestra online promovida pela Universidade Federal da Bahia, na mesa de abertura intitulada "Educação: desafios do nosso tempo" do evento Congresso Virtual UFBA 2020, em maio de 2020. Disponível em: https://www.youtube.com/watch?v=6w0vELx0EvE.

\section{plurais}


com os professores, repete os conteúdos e não leva em conta a variação de competência digital entre eles" (KOCHHANN, 2020, n.p.).

Os dados alarmantes apresentados pela pesquisa e destacados anteriormente, além de sinalizarem desigualdades estruturais e materiais, apontam para problemas de formação, a qual pode impossibilitar que as tecnologias digitais sejam incorporadas pelos docentes em suas práticas pedagógicas. Ademais, esse estudo nos revela que a maioria dos docentes que ensina Matemática na Educação Básica não tem acesso a essas tecnologias ou não tiveram contato com elas durante a sua formação inicial e continuada.

Diante desses dados, alguns questionamentos são suscitados, dentre eles, destacamos: como, em um contexto de distanciamento social, promover aprendizagens matemáticas acessíveis a partir de um ensino remoto e do uso de ferramentas tecnológicas que se desconhecem? Perante a esse questionamento, abordaremos na próxima seção aspectos relacionados às tecnologias digitais no contexto educacional.

\section{As tecnologias digitais e o contexto pandêmico}

Estamos vivendo um período em que os olhares se direcionaram para as tecnologias e no como os processos de ensino e aprendizagem acontecem, ou deveriam acontecer, pela mediação tecnológica. No entanto, pensamos ser pertinente iniciar essa discussão considerando que as escolas brasileiras já não têm seus parques tecnológicos atualizados há mais de 10 anos, a exemplo da principal e mais longa política de governo, conhecida como Programa Nacional de Tecnologia Educacional - Proinfo (BRASIL, 2012). Esse programa foi criado em 1997 pelo Ministério da Educação (MEC) e desde 2015 não divulga informações sobre suas atividades. No entanto, por intermédio dele as escolas públicas do país receberam computadores, projetores, lousas, tablets e outros recursos tecnológicos, além de formação continuada para professores, realizadas pelos Núcleos de Tecnologia Educacional (NTE), que também acompanham o desenvolvimento de projetos nas escolas.

Nessa direção, perante o contexto pandêmico, nos questionamos se as tecnologias digitais e os cursos de formação continuada, disponibilizados no transcorrer dos anos, entendendo a problemática que apresentamos no parágrafo anterior, foram suficientes para preparar os docentes 
brasileiros para as atividades de ensino remoto. Neste momento, não temos uma resposta para tal inquietude, e entendemos a necessidade de uma pesquisa empírica para isso, mas o que percebemos pelas nossas leituras, como a de Kochhann (2020) que apresentamos na seção anterior, é a grande dificuldade da rede de ensino encontrar, de imediato, uma solução, de modo a diminuir os impactos causados na aprendizagem dos estudantes devido ao distanciamento social; mas, ao mesmo tempo, podemos perceber o esforço da rede em buscar estratégias que possibilitem a comunicação entre professores e estudantes, de modo a os inserirem no "novo normal".

Destacaremos então, algumas ferramentas e espaços que podem auxiliar professores e estudantes neste processo de interação e construção do conhecimento, sobretudo para o ensino e aprendizagem da Matemática; a saber: os Ambientes Virtuais de Aprendizagem (AVA), os softwares educativos, as redes sociais, as ferramentas de construção e colaboração em rede, entre outras que permitem o envio e recebimento de mensagens, atividades e discussões, tanto em grupo quanto individuais e em diferentes formatos, isto é, em vídeos, imagens, texto ou voz.

Vale destacar que, cada uma dessas ferramentas e espaços, nos apresenta um leque de possibilidade e sobre elas nos deteremos. As entendemos enquanto espaços de aprendizagem importantes nesse contexto de pandemia e as apresentaremos enquanto caminhos possíveis para o desenvolvimento do conhecimento matemático.

Iniciaremos esse apresentar pelo AVA, no qual há inúmeras ferramentas de interação, tais como: os chats, fóruns de discussão, espaços de webconferências, entre outros. E, para realização de atividades, destacamos os espaços para inserção de vídeos, links, hiperlinks, textos, apostilas, estudos dirigidos, questionários, enquetes, bem como os destinados ao recebimento das tarefas realizadas pelos estudantes. Conforme destacado por Kenski (2003), esses espaços são definidos como escolas virtuais que nos são apresentados na tela do computador, na forma de imagens e links e se configuram de maneira “(...) fluida, mutante, a escola virtual é um ícone de um novo tempo tecnológico do espaço educativo” (KENSKI, 2003, p. 55).

No decorrer dos anos, algumas universidades e escolas tiveram a oportunidade de desenvolver projetos com o uso desses espaços virtuais, tornando-os extensões da sala física, mas em outras situações, esses espaços foram usados apenas como repositórios de conteúdos. Nesse sentido, faz-se necessário ter cuidado, uma vez que o depositar materiais não é garantia de aprendizagem.

\section{plurais}


Ressaltamos que, os processos de ensino e aprendizagem demandam de interação e discussão para que os estudantes possam construir os conhecimentos e os professores possam mediar esse processo.

Em relação aos vídeos educacionais, salientamos que podem ser produzidos pelos próprios professores, contribuindo para um movimento de formação que parte da reflexão sobre a própria práxis pedagógica; ou ainda, serem produzidos ou selecionados pelos estudantes e publicados em espaços próprios para a sua disponibilização como, por exemplo, o YouTube.com. Segundo Moran (1995) e Tena (2014) o uso dos vídeos na educação apresenta grandes potencialidades e podem ser utilizados em diferentes níveis e modalidades de ensino.

Segundo os autores, os vídeos podem propiciar momentos de: descontração para os estudantes; oportunidade para introdução do conteúdo; espaço para discussões sobre o assunto apresentado; possibilidade de rever o conteúdo do vídeo mais de uma vez, realizando pausas quando necessário e retornando pontos para discussão que, porventura, não tenham ficado claros. No contexto atual, os vídeos estão sendo usados frequentemente, isso no formato de lives, em redes sociais, com a interação dos participantes em tempo real, de modo a esclarecer dúvidas e contribuir com o assunto apresentado, algo que julgamos, diante a uma realidade de ensino remoto, importante nos processos de ensinar e aprender Matemática.

Para a produção dos vídeos, tanto os professores quanto os estudantes, podem valer-se dos celulares, sendo uma das tecnologias mais populares do mundo, e atualmente, um dos recursos mais utilizados pelos estudantes. Segundo Nalini $(2017$, p. 1) “[...] o ensino prelecional está sendo questionado em todos os ambientes. Se quisermos manter o aluno interessado em aprender, temos de usar a linguagem dele. A linguagem de seu tempo". Desse modo, com o suporte do celular é possível acessar os AVA, enviar e receber tarefas, acessar aplicativos que explorem conteúdos matemáticos e outros, além de permitir também, interação e comunicação entre os envolvidos nos processos de ensino e aprendizagem.

Outra ferramenta tecnológica que pode contribuir para as atividades remotas, nesse momento de distanciamento social, são os softwares educativos, disponibilizados em ambientes on-line ou aplicativos, como o Geogebra que possibilita a abordagem de geometria dinâmica e pode ser instalado no computador ou no celular. Segundo Nogueira (2015, p. 58), “[...] uma das vantagens deste software é o fato de ser possível representar, em sua tela principal, a parte geométrica e algébrica de 
todas as construções matemáticas e poder modificá-las dinamicamente, caso seja necessário". Outro software, que merece destaque é o Scratch, caracterizado por ser uma linguagem de programação capaz de desenvolver o raciocínio lógico, habilidades matemáticas e a criatividade (OLIVEIRA, 2009). Além desses, inúmeros outros softwares no formato de aplicativos matemáticos são disponibilizados na internet, tanto para computadores quanto para celulares.

Nesse contexto, destacamos também o podcast, tecnologia disponibilizada na internet em formato de áudio que consiste em um “(...) modo de produção/disseminação livre de programas distribuídos sob demanda e focados na reprodução de oralidade, também podendo veicular músicas/ sons" (FREIRE, 2013, p. 47). Assim, os podcasts trazem uma discussão oral, realizada por uma pessoa sobre determinada temática, podem contribuir para o debate e a disseminação de informações, como exemplo, no âmbito do ensino de Matemática, destacamos o projeto "Matemática em Conta-gotas" (VENTURA, 2020, n.p.) desenvolvido por um professor e destinado aos estudantes com deficiência visual.

Vale destacar que, o acesso à internet é algo essencial para a utilização dessas e outras ferramentas e espaços de aprendizagem. Entretanto, sabemos que o Brasil é um país com inúmeras desigualdades e, nesse período, em que as atividades foram sendo propostas com a mediação de tecnologias digitais, constatou-se que muitos estudantes ficaram de fora dos processos de ensino e aprendizagem, seja pela falta de recursos tecnológicos ou de acesso a internet mínima para navegação. Desse modo, não basta apenas pensarmos em um meio de comunicação e interação que possa atrair os estudantes, faz-se necessário pensar sobre a acessibilidade dos meios tecnológicos e da internet, para que todos possam participar ativamente da construção do seu conhecimento.

Tendo em vista as tecnologias apresentadas anteriormente, defendemos que, com o suporte das tecnologias digitais, podemos ensinar e aprender não só em nossas salas de aulas físicas, mas também em espaços on-line, com a mediação de recursos digitais que nos permitem interagir, comunicar, aprender no tempo e no espaço que tivermos disponíveis, de modo individual ou colaborativo. No entanto, faz-se necessário considerarmos que a educação deve ser pensada para todos e por todos, assim a educação deve ser inclusiva. Na continuidade, destacamos os aspectos relacionados à inclusão, considerando o atual cenário educacional.

\section{plurais}




\section{A reafirmação dos desafios da Educação Inclusiva no atual contexto escolar}

Por conta da pandemia do novo coronavírus, muitas instituições de ensino estão organizando suas atividades de maneira remota, algumas com a utilização de tecnologias digitais; frente a isso, perguntamo-nos: será que todos os estudantes, das mais diversas partes do país possuem acesso? Como possibilitar a acessibilidade para esses estudantes? Ou ainda, como possibilitar a acessibilidade das aulas apresentadas nas redes de televisão para os estudantes surdos? Como favorecer o processo de visualização matemática para estudantes com deficiência visual em atividades de ensino remoto?

Ressaltamos que, as discussões relacionadas à inclusão na educação brasileira não são recentes, datam do início dos anos de 1990 e foram sendo reafirmadas pelas inúmeras lutas de construção de um “(...) projeto fundamentalmente crítico" (SLEE, 2011, p. 203), em prol daqueles que eram colocados à margem da sociedade e das oportunidades. Ao discorrermos sobre a inclusão, estamos considerando-a em sua forma ampla, ou seja, inclusão que perpassa pelas diversas Necessidades Educacionais Específicas (NEE), isto é, pessoas: com deficiência física, visual, auditiva, entre outras deficiências; com restrição de liberdade; oriundas de comunidades carentes; pertencentes a comunidades quilombolas, indígenas, ou outros grupos que tiveram seus direitos relegados por inúmeros anos.

Até chegarmos à compreensão da necessidade de se efetivar a inclusão na educação, passamos por inúmeros processos, sendo enfatizado por Mantoan $(2008$, p. 29) que "[...] os caminhos até então percorridos para que a escola brasileira acolha a todos os estudantes, indistintamente, têm se chocado com o caráter eminentemente excludente, segregado e conservador de nosso ensino, em todos os seus níveis". Com a vivência do momento pandêmico, ficou ainda mais explícito o caráter excludente, segregador e conservador da maioria das instituições educacionais brasileiras, as quais agora se vêm com uma grande parcela de estudantes que necessitam de acessibilidade para que possam participar ativamente do seu processo de construção do conhecimento.

Vale ressaltar que, Nery e Sá (2019), já defendiam que as escolas regulares deveriam acolher os estudantes, nas suas variadas especificidades, e estarem aptas a possibilitar a acessibilidade a toda comunidade, superando assim, os modelos educativos pautados na homogeneidade e nas práticas segregadoras do ensino “(...) contribuindo com a construção de uma sociedade inclusiva 
que desmistifique a ideia de normalidade e o discurso homogeneizante da igualdade que nega a diferença e a diversidade" (NERY; SÁ, 2019, p. 4).

Ao explicitarmos a necessidade das instituições de ensino ter acessibilidade, estamos considerando a definição da Lei Brasileira de Inclusão da Pessoa com Deficiência que expressa que a:

[...] possibilidade e condição de alcance para utilização, com segurança e autonomia, de espaços, mobiliários, equipamentos urbanos, edificações, transportes, informação e comunicação, inclusive seus sistemas e tecnologias, bem como de outros serviços e instalações abertos ao público, de uso público ou privados de uso coletivo, tanto na zona urbana como na rural, por pessoa com deficiência ou com mobilidade reduzida (BRASIL, 2015, p. 01).

A acessibilidade na Lei Brasileira de Inclusão da Pessoa com Deficiência (BRASIL, 2015), leva em consideração o acesso aos bens, serviços, informação e comunicação, pelas pessoas que possuem alguma deficiência, entretanto, ao discorrermos sobre a inclusão na perspectiva que nos propomos neste artigo, estamos considerando que a acessibilidade e a utilização desses bens, serviços, informações e comunicações devem ser oferecidos a todos.

Vale ressaltar que, a acessibilidade vai além do acesso, tendo em vista que atualmente a Lei de Diretrizes e Bases da Educação Nacional (BRASIL, 1996, p. 10) assegura em seu artigo quinto que “(...) o acesso à educação básica obrigatória é direito público subjetivo”, isto é, todos os cidadãos brasileiros possuem acesso à educação. No entanto, nem todos os espaços e as práticas desenvolvidas nas instituições de ensino estão acessíveis, por isso, a educação inclusiva vem reafirmar a necessidade do reconhecimento de que todos nós tenhamos o direito de sermos “(...) iguais quando a diferença nos inferioriza; temos o direito a ser diferente quando a igualdade nos descaracteriza" (SANTOS, 2006, p. 462).

No âmbito do ensino de Matemática, desde a criação do Grupo de Trabalho 13 (GT 13), intitulado "Diferença, Inclusão e Educação Matemática", pela Sociedade Brasileira de Educação Matemática, cujo objetivo é “(...) agregar pesquisadores preocupados com o desenvolvimento de uma Educação Matemática 'para todos', na qual as particularidades associadas às práticas matemáticas dos diferentes aprendizes são valorizadas e entendidas" (SOCIEDADE BRASILEIRA DE EDUCAÇÃO MATEMÁTICA, 2020, n.p.), constata-se que vêm sendo desenvolvidas pesquisas

\author{
plurais


com o intuito de possibilitar a acessibilidade para todos os estudantes no ensino de Matemática e começa-se a intensificar os debates em torno da Educação Matemática Inclusiva.

Salientamos que a Educação Matemática Inclusiva busca assegurar que os estudantes tenham acesso aos conhecimentos matemáticos trabalhados no contexto educacional e que possam contribuir com a formação de cidadãos participativos e atuantes na sociedade e no meio em que vivem, contemplando assim, com a competência descrita na Base Nacional Comum Curricular, quanto ao “(...) utilizar estratégias, conceitos e procedimentos matemáticos para interpretar situações em diversos contextos [...] de modo a contribuir para uma formação geral” (BRASIL, 2018, p. 531).

Assim, o ensino de Matemática para todos pressupõe que as estratégias e os conhecimentos matemáticos aprendidos possam contribuir na interpretação das informações apresentadas em outros contextos e em nosso cotidiano, considerando-se que estamos imersos na sociedade da informação e comunicação e que somos, a todo instante, engolfados por novas notícias, a uma velocidade inimaginável, que exigem de nós conhecimento para interpretá-las com criticidade e destreza.

Destarte, o momento pandêmico nos apresenta a necessidade de efetivarmos uma educação matemática que contemple a todos. Além de nos apresentar que o ensino de Matemática desenvolvido nos moldes anteriores à pandemia, não dá conta de atender as demandas da sociedade contemporânea, ou ainda, como defendido por Arendt (2011, p. 243) "[...] estamos sempre educando para um mundo que ou já está fora dos eixos ou para aí caminha”. Dito de outra forma, a educação matemática necessita estar em consonância com as demandas de cada geração, pois a cada instante, passamos por transformações e progressos realizados pelas pessoas, que são influenciadas pela educação, e que a ela, devem também influenciar, por isso, necessitamos pensar práticas educacionais acessíveis.

\section{A interseção dos temas perante o "novo normal"}

Com o início da pandemia no Brasil, a sociedade esperou da escola, uma estratégia rápida e eficiente para dar suporte aos estudantes durante o distanciamento social. Com o momento pandêmico, temos um cenário educacional, no qual, as escolas precisaram suspender as atividades presenciais e pensar em outras estratégias de ensino e aprendizagem. 
O movimento de valorização das atividades remotas irrompe dessa situação, como sinaliza Silva (2020, no prelo), e o caráter da excepcionalidade as apresenta não só como alternativa acessível, mas também possível a todos os estudantes e professores, de forma equânime e em todos os cenários educacionais, o que não é verdade. Temos inúmeras especificidades que necessitam ser consideradas para o planejamento de um trabalho remoto.

Vale ressaltarmos, que o trabalho remoto ou ensino remoto corresponde à atividade/labor docente que pressupõe um distanciamento geográfico de professores e estudantes (MOREIRA; SCHLEMMER, 2020). Esse pode ser mediado pelas tecnologias digitais ou outras ferramentas que possam auxiliar na garantia do distanciamento entre os agentes envolvidos nos processos de ensino e aprendizagem. Entretanto, faz-se necessário assegurar que todos possam ter acesso aos meios pelos quais se está valendo nesse momento de distanciamento.

Diante da compreensão de ensino remoto e por acreditarmos que as tecnologias digitais podem contribuir para a efetivação desse distanciamento geográfico entre as pessoas, é que nos propusemos a discutir no âmbito deste artigo, a formação de professores que ensinam Matemática, o uso de tecnologias digitais e a educação inclusiva, de modo a tentar compreender o contexto atual e, ao mesmo tempo, nos prepararmos para vivenciarmos o "novo normal" na educação.

Nesse momento, nos propomos a tecer as intersecções entre essas temáticas. De início, destacamos que para o uso das tecnologias digitais e para a efetivação da educação inclusiva, os professores necessitam ser formados - formação que pode ser vivenciada desde os primeiros anos de construção da identidade docente que vai ao longo da vida sendo construída e consolidada, principalmente nos espaços escolares, locais de vivência da práxis pedagógica.

O que se constatou com o atual contexto é que muitos professores, dentre eles, os de Matemática, foram surpreendidos por essa transição (im)posta pela pandemia de um ensino presencial para o remoto. Para muitos, essa transição se deu sem planejamento e sem considerar as diferentes realidades, inclusive materiais e de formação. A maior parte dos professores brasileiros, como assevera Dellagnelo (2020, n.p.), “[...] não foi preparada para integrar tecnologia nos processos de ensino aprendizagem e para ensinar de forma on-line"; o que, ainda segundo a autora, faz surgir, mais uma vez, um alerta para necessidade de incluir essa temática na formação inicial e continuada dos professores.

\section{plurais}


Frente à necessidade de formação para o uso das tecnologias digitais, encontra-se a inevitabilidade das tecnologias estarem acessíveis a todos. Assim, é preciso que os estudantes e professores tenham as ferramentas tecnológicas necessárias e os meios para a sua utilização, dentre eles, destacamos a internet de qualidade para todos, mas só isso não é suficiente.

Existem estudantes que carecem de muito mais do que o simples fornecimento de internet, precisam de acessibilidade, como por exemplo, para as pessoas com deficiência visual, as ferramentas devem possuir ledores de tela e os vídeos audiodescrição, além dos materiais serem apresentados em um formato em que o ledor de tela possa realizar a leitura. E ao nos referirmos aos estudantes e professores com deficiência auditiva, requerem dentre outras coisas, mecanismos com tradução para a Língua Brasileira de Sinais- Libras. Essas e outras acessibilidades fazem-se necessárias, contudo o que irá ditar qual a acessibilidade a ser oferecida será a NEE que os estudantes e professores possam ter. Mas, as instituições de ensino e os professores, enquanto mediadores do conhecimento devem estar atentos aos contextos de sua inserção e as especificidades da sua comunidade.

Assim, com as demandas apresentadas pelo momento de pandemia ficou ainda mais explícita a necessidade de se construir práticas pedagógicas inclusivas, que possam atender a todos, sem distinção, tanto que, estamos constantemente ouvindo slogans de instituições de ensino que apregoam o fato de que ninguém será deixado para trás, que a educação será efetivada para todos. São discursos que explicitam o fato da inclusão ainda não se constituir enquanto uma prática efetiva, mas que a cada dia se mostra necessária e urgente. Nesse contexto, concordamos com Diniz (2012, p. 31) quando aborda que a inclusão deve ser estabelecida “[...] como um processo de mudança e de reestruturação das escolas como um todo, com o objetivo de assegurar que todos os(as) alunos(as) possam ter acesso a todas as oportunidades educacionais e sociais oferecidas pela escola".

Aprofundando os aspectos que se fazem presentes nas instituições de ensino, Diniz (2012) enfatizou que a inclusão perpassa também pelo: currículo, avaliação, registros de classe, práticas docentes, tecnologias digitais, enfim pela formação docente, seja inicial ou continuada. Assim, a inclusão gera uma reviravolta no ensino que pode vir a contribuir não somente para os estudantes que possuem alguma NEE, mas com todos os agentes envolvidos nos processos educativos.

Tendo em vista que, ao se pensar em um ensino para todos, as práticas tradicionais perdem o seu lugar e a espera pelo estudante ideal acaba, pois a aprendizagem é para todos, não somente 
para aqueles que têm familiaridade com uma certa tecnologia digital, perante a um determinado conteúdo ou que possuem uma condição socioeconômica que favoreça o acesso aos recursos e conteúdos de modo a desenvolver os processos de ensino e aprendizagem.

\section{Considerações finais}

Este artigo, resultado de um caminhar teórico, buscou refletir sobre os impactos e desafios impostos no momento atual de pandemia para a formação dos professores que ensinam Matemática no que se refere à efetivação de uma prática inclusiva com o uso das tecnologias digitais. Na introdução do texto, algumas inquietudes foram apresentadas e tentamos ampliar o olhar a partir do que apresentaram alguns autores. Não foi nossa pretensão esgotar as discussões ou "aprisionar a realidade" neste recorte que apresentamos; pelo contrário, muito ainda tem-se a dizer.

Entendemos, a partir do que discorremos ao longo do texto, que para desenvolver um ensino de Matemática que possa contemplar a todos, em todas as suas singularidades, faz-se necessário, a priori, que os professores tenham uma formação adequada e lhes sejam possibilitadas condições favoráveis de materiais e de trabalho. O momento de pandemia revelou um quantitativo considerável de escolas e professores que nunca utilizaram tecnologias para mediar os processos de ensino e aprendizagem da Matemática.

Ensinar Matemática em um regime de atividades remotas sem formação adequada, sem estrutura e condições materiais e de trabalho são, para nós, os principais desafios enfrentados hoje pelas escolas, professores e estudantes brasileiros. Assim, torna-se imprescindível, nesse movimento (re)pensar essas questões, considerar a necessidade de políticas públicas para a formação e prática docente, e que essas temáticas efetivamente componham os currículos escolares e de formação de professores.

A Educação Matemática, nesse ínterim, pode contribuir para o (re)pensar desse momento de pandemia, sobretudo, a partir da construção de um percurso de intervenção no mundo, de maneira progressista, na qual a própria Matemática seja o elemento capaz de estimular e materializar os avanços necessários a atual e as futuras gerações. Para isso, portanto, vale considerar a perspectiva da Matemática humanista enquanto um caminho possível para a construção do "novo normal".

\section{plurais}


Diante o exposto até aqui, esperamos que esta leitura reverbere no (re)pensar as políticas de formação e prática dos docentes que ensinam Matemática. Outros olhares podem ser lançados sobre os questionamentos que apresentamos e, nesse sentido, pensamos ser necessário que pesquisas que articulem essas dimensões (formação, tecnologia e inclusão) sejam construídas para que, partindo de dados empíricos, outras discussões sejam feitas.

\section{REFERÊNCIAS}

ARENDT, H. A crise na Educação. Em ARENDT, Hannah. Entre o passado e o futuro. Tradução de Mauro W. Barbosa. 7. ed. São Paulo: Perspectiva, 2011, p. 221-247.

BRASIL. Lei de Diretrizes e Bases da Educação Nacional: Lei 9.394, de 20 de dezembro de 1996. Extraída de http://www.planalto.gov.br/ccivil_03/leis/19394.htm. Acesso em: 25 junho 2020.

BRASIL. Fundo Nacional de Desenvolvimento da Educação: ProInfo, 2012. Extraída de http:// www.fnde.gov.br/programas/programa-nacional-de-tecnologia-educacional-ProInfo. Acesso em 26 junho 2020.

BRASIL. Resolução CNE/CP n 2, de 01 de julho de 2015. Define as Diretrizes Curriculares Nacionais para a formação inicial em nível superior e para a formação continuada. Brasília, DF, 2015. Extraída de http://portal.mec.gov.br/docman/agosto-2017-pdf/70431-res-cne-cp-00203072015-pdf/file. Acesso em 28 junho 2020.

BRASIL. Lei Brasileira de Inclusão da Pessoa com Deficiência: Lei 13.146, de 6 de julho de 2015. Extraída de http://www.planalto.gov.br/ccivil_03/_ato2015-2018/2015/lei/113146.htm. Acesso em: 25 de junho 2020.

BRASIL. Base Nacional Comum Curricular: educação é a base. Brasília: Ministério da Educação. 2018. Extraída de http://basenacionalcomum.mec.gov.br/images/BNCC_EI_EF_110518_ versaofinal_site.pdf. Acesso em 25 junho 2020.

CECCO, B. L.; BERNARDI, L. T. M. S; DELIZOICOV, N. C. Formação de professores que ensinam Matemática: um olhar sobre as redes sociais e intelectuais do BOLEMA. Bolema, Rio Claro (SP), v. 31, n. 59, 2017, p. 1101-1122.

DELLAGNELO, L. Escolas conectadas: aprendizagem em tempos de coronavírus. Revista e Educação. 2020. Extraída de https://revistaeducacao.com.br/2020/03/17/aprendizagem-coronavirus/. Acesso em: 27 junho 2020. 
DINIZ, M. Inclusão de pessoas com deficiência e/ou necessidades específicas: avanços e desafios. Belo Horizonte: Autêntica, 2012.

FABRE, M. Penser la formation. Paris: PUF, 1995.

FIORENTINI, D. et al. Formação de professores que ensinam matemática: um balanço de 25 anos de pesquisa brasileira. Em Educação em Revista, Belo Horizonte, p. 137-159, 2002.

FIORENTINI, D; PASSOS, C. L. B. P.; LIMA, R. C. R. Mapeamento da pesquisa acadêmica brasileira sobre o professor que ensina matemática: período 2001 - 2012. Campinas: FE/Unicamp, 2016.

FORMOSINHO, J. Formação contínua de professores: realidades e perspectivas. Aveiro: Universidade de Aveiro, 1991.

FREIRE, P. Pedagogia da autonomia: saberes necessários à prática educativa. 48. ed. Rio de Janeiro: Paz e Terra, 2014.

FREIRE, E. P. A. Conceito educativo de podcast: um olhar para além do foco técnico. Em Educação, Formação \& Tecnologias, Caparica, PT: FCT, v. 6, n. 1, p. 35-51, 2013. Extraída de https://eft.educom.pt/index.php/eft/article/view/340 Acesso em: 26 junho 2020.

GATTI, B. Formação de professores no Brasil: características e problemas. Em Educação e Sociedade, Campinas, v. 31, n. 113, out./dez. 2010, p. 1355-1379.

GATTI, B; BARRETO, E. S. S; ANDRÉ, M. E. D. A; ALMEIDA, P. C. A. Professores no Brasil: novos cenários de formação. Brasília: UNESCO, 2019.

KOCHHANN, L. E. Lúcia Dellagnelo: a educação básica antes, durante e depois da pandemia. Em Desafios da Educação. 2020. Extraída de: https://desafiosdaeducacao.grupoa.com.br/lucia-dellagnelo-educacao-basica/. Acesso em 27 junho 2020.

KENSKI, V. M. Tecnologias e ensino presencial e a distância. Campinas: Papirus, 2003.

MANTOAN, M. T. E. (Org.). O desafio das diferenças nas escolas. Petrópolis: Vozes, 2008.

MORAN, J. M. O Vídeo na Sala de Aula. Em Comunicação e Educação, v. 2, p. 27-35, 1995.

MOREIRA, J. A.; SCHLEMMER, E. Por um novo conceito e paradigma de educação digital online. Em Revista UFG, v. 20, 2020, p. 1-35. Extraída de https://www.revistas.ufg.br/revistaufg/article/view/63438/34772. Acesso em: 27 junho 2020.

\section{plurais}


NALINI, J. R. Aprovada a lei que libera o uso de celular nas escolas estaduais de São Paulo. 2017. Extraída de https://www.educacao.sp.gov.br/noticias/aprovada-lei-que-libera-o-uso-do-celular-em-escolas-estaduais-de-sp/. Acesso em: 26 junho 2020.

NERY, E. S. S; SÁ, A. V. M. A deficiência visual em foco: estratégias lúdicas na Educação Matemática Inclusiva. Em Revista Educação Especial, v. 32, 2019, p. 1-26. Extraída de https:// periodicos.ufsm.br/educacaoespecial/article/view/35402/pdf. Acesso em: 25 jun. 2020.

NOGUEIRA, C. A. Ensino de geometria: concepções de professores e potencialidades de ambientes informatizados. Dissertação (Mestrado em Educação) - Universidade de Brasília, Brasília, 2015.

OLIVEIRA, E. C. L. O uso do software scratch no ensino fundamental: possibilidades de incorporação curricular segundo professoras dos anos iniciais. Dissertação (Mestrado em Educação). Pontifícia Universidade Católica de Minas Gerais, Belo Horizonte, 2009.

PIMENTA, S. G. Formação de professores: Identidade e saberes da docência. Em PIMENTA, S. G. Saberes pedagógicos e atividade docente. São Paulo: Cortez, 1999. p. 15-34.

SANTOS, V. M. O Desafio de Tornar-se Professor de Matemática. Em NUANCES: estudos sobre educação. ano VIII, n. 8. set. 2002. Extraída de https://revista.fct.unesp.br/. Acesso em: 27 junho 2020.

SANTOS, B. S. Para uma concepção intercultural dos direitos humanos. Em SANTOS, B. S. A gramática do tempo: para uma nova cultura política. São Paulo: Cortez, 2006, p. 433-470.

SANTOS, B. S. A cruel pedagogia do vírus. Coimbra: Almedina, 2020.

SILVA, A. J. N. S. Querido diário... o que revelam as narrativas sobre ludicidade, formação e futura prática do professor que ensina(rá) matemática nos anos iniciais. Tese (Doutorado em Educação) - Universidade Federal de São Carlos, campus São Carlos, São Carlos. 2018.

SILVA, A. J. N.; PASSOS, C. L. B. Formação do professor que ensina matemática, ludicidade e narrativas: o que se pesquisou no Brasil. Em Revista Eletrônica de Educação (São Carlos), v. 14, p. 1-20, 2020.

SLEE, R. O paradoxo da inclusão: a política cultural da diferença. Em APPLE; M. W.; AU, W.; GANDIN, L. A. Educação crítica: análise internacional. Trad. Vinícius Figueira. Porto Alegre: Artmed, 2011, p. 203-216. 
SOCIEDADE BRASILEIRA DE EDUCAÇÃO MATEMÁTICA. GT13: Diferença, Inclusão e Educação Matemática. 2020. Extraída de http://www.sbembrasil.org.br/sbembrasil/index.php/ grupo-de-trabalho/gt/gt-13. Acesso em: 25 junho 2020.

TENA, R. R. El video, una herramienta para la enseñanza. Em PEREIRA, Josias. (Org.). Produção de Vídeos nas Escolas: Uma visão Brasil - Itália - Espanha - Equador. Pelotas: ERD Filmes, 2014. p. 71-97.

VENTURA, L. A. S. Professor cria podcast de matemática para pessoas com deficiência visual. 2020. Extraída de https://brasil.estadao.com.br/blogs/vencer-limites/professor-cria-podcast-de-matematica-para-pessoas-com-deficiencia-visual/\#: :text=Isto $\% 20 \mathrm{obriga} \% 20 \mathrm{o} \% 20$ professor\%20a,para\%20pessoas\%20com\%20defici\%C3\%AAncia\%20visual. Acesso em: 27 junho 2020.

Recebido em: 30 de junho de 2020.

Inserido em: 10 de agosto de 2020.

Esta obra está licenciada com uma Licença Creative Commons Atribuição 4.0 Internacional. 